УДК 504.75

DOI: $10.18101 / 1994-0866-2020-1-4-12$

\title{
НА ПУТИ К УСТОЙЧИВОМУ РАЗВИТИЮ МИРА: КОММУНИТАРИСТСКАЯ СТРАТЕГИЯ ЖИЗНЕУСТРОЙСТВА СООБЩЕСТВ ЛЮДЕЙ
}

\author{
(C) Мантатов Вячеслав Владимирович, \\ доктор философских наук, профессор, \\ заведующий кафедрой ЮНЕСКО по экологической этике \\ Восточно-Сибирский государственный университет технологий и управления \\ Россия, 670013, г. Улан-Удэ, ул. Ключевская, 40в \\ E-mail: unesco03bur@gmail.com
}

\author{
(C) Мантатова Лариса Вячеславовна \\ доктор философских наук, профессор, \\ заведующая кафедрой философии, истории и культурологии, \\ Восточно-Сибирский государственный университет технологий и управления \\ Россия, 670013, г. Улан-Удэ, ул. Ключевская, 40в \\ E-mail: mantatovalarisa@mail.ru
}

В данной статье дается анализ концепции коммунитаризма как альтернативы неолиберализма, в контексте разработки новой стратегии устойчивого развития мира. Коммунитаризм развивает идею морального совершенствования общества на основе возрождения традиционных ценностей, идею высокой гражданственности лидеров государств и подлинной демократической подотчетности государственных служащих. Ведущим подходом к исследованию данной проблемы является метод философской рефлексии, позволяющий выявить основания и перспективы различных стратегий жизнеустройства сообществ людей. По мнению авторов статьи, наиболее реалистичной и легитимной, стратегемной и алгоритмичной теорией мирового развития является концепция устойчивого развития, продвигаемая $\mathrm{OOH}$; в то же время в статье отмечается недостаточная определенность и разработанность социальных технологий такого развития. Материалы статьи представляют практическую ценность для разработки путей перехода российского общества к устойчивому развитию.

Ключевые слова: стратегия; жизнеустройство; коммунитаризм; неолиберализм; устойчивое развитие.

\section{Для цитирования}

Мантатов В. В., Мантатова Л. В. На пути к устойчивому развитию мира: коммунитаристская стратегия жизнеустройства сообществ людей // Вестник Бурятского государственного университета. Философия. 2020. Вып. 1. С. 4-12.

Сегодня в науке идет интенсивный поиск теории мирового развития. Одной из последних научных работ в этом направлении является социальная теория английского философа Майкла Манна, которого ученые Запада сравнивают с Максом Вебером [17, p. 150]. Особой заслугой и спецификой данной теории является критика господствующей ныне в мире неолиберальной доктрины мирового раз- 
B. В. Мантатов, Л. В. Мантатова. На пути к устойчивому развитию мира: коммунитаристская стратегия жизнеустройства сообществ людей

вития. Майкл Манн, в частности, доказывает, что неолиберальная реформа, выбранная руководством Российской Федерации, является неудачной стратегией развития в отличие от современной политики Коммунистической партии Китая [18, p. 510; 19, p. 190; 20, p. 197].

На наш взгляд, наиболее приемлемой концепцией мирового развития и альтернативой неолиберализма является стратегия устойчивого развития, продвигаемая $\mathrm{OOH}$. По форме эта концепция является общецивилизационной и планетарной, стратегемной и алгоритмичной, реалистичной и легитимной теорией мирового развития $[8$, с. $3 ; 9$, с. 3].

«По содержанию это симбиоз всемирного и локального развития; гармоничное и неразрывное единство экономического, экологического и социального развития; полное экологобезопасное социоприродное развитие; формирование безотходной, энерго- и материалосберегающей, экологически безвредной, социально эффективной экономической системы; стремление к справедливому распределению социальных благ, удовлетворению базовых социальных потребностей в образовании, здравоохранении, социальном обеспечении; нравственное «перерождение» людей; появление поколений, руководствующихся вновь созданной системой гуманистических ценностей; сохранение Земли, пригодной для будущих поколений; обеспечение безопасности через устойчивое развитие; обеспечение сохранности языка, культуры, традиций и верований всех народов. По значимости каждого из названных пунктов для перехода к устойчивому развитию, - пишет Х. А. Барлыбаев, - можно дать следующий порядок их расположения:

1) нравственное возрождение людей как исходное обязательное условие;

2) обеспечение экологической безопасности как важнейший императив;

3) экономические преобразования как основа формирования устойчивого общества;

4) реализация политических предпосылок устойчивого мирового развития» [1, с. 96].

Словом, переход общества к устойчивому развитию предполагает коренное изменение общественного бытия и общественного сознания, способов жизнедеятельности всех слоев народонаселения.

Гуманистический императив стратегии устойчивого развития состоит в нахождении правильного баланса между конкурентными (рыночными) и солидарными отношениями, между экономической эффективностью капитализма и социальной справедливостью социализма. Как известно, именно такой путь устойчивого развития предлагает китайскому народу Коммунистическая партия Китая.

Коммунитаристский перфекционизм как предпосылка устойчивого человеческого развития (по материалам дискуссии «коммунитаризм versus неолиберализм»)

Современный мир - это мир господства капитала, где практически безальтернативно практикуемой идеологической концепцией является неолиберализм. В данном контексте среди основных его положений мы выделим следующие: 
a) нет общества как такового - есть только отдельные индивиды, которые вынуждены принимать личные решения; б) люди могут быть связаны только формальными отношениями купли-продажи; в) главные жизненные установки людей - это потребление материальных благ и личное обогащение, борьба за выживание и личный успех.

Концептуальными источниками неолиберализма являются социалдарвинизм и философский номинализм. Маргарет Тэтчер произнесла фразу: «Нет такой вещи, как общество» $[14$, с. 15]. Это означает, что есть только частные интересы собственников, волю которых должна выполнять железная рука Левиафана (государства). В основе идеологии тэтчеризма, которая стала руководством к действию российских неолибералов, лежит культ личного успеха и личного богатства. По мнению английских ученых, в результате правления неолибералов «великие традиции демократии, доверия, взаимности и реципрокности оказались почти полностью уничтожены» [12, с. 550]. Возрождается культ частного интереса и эгоизма, который поддерживается государством.

Неолибералы как идеологи капитализма возвели в абсолют все материальное и объявили утопией все идеальное, духовное, возвышенное. Как писал поэт Ф. Тютчев, «чем либеральнее, тем пошлее». В условиях господства капитала люди становятся инструментами потребительского рынка. Капитализм - это «цивилизация денег», где деньги приобрели зловеще важную роль.

Неолиберальные идеологи капитализма не смогли предложить миру никакой разумной стратегии жизни, кроме потребительского эгоцентризма, индивидуального и группового эгоизма. При этом они пытаются использовать некоторые генетические доктрины (типа «теории эгоистичного гена») для оправдания биологического и социального расизма. В среде неолиберальной публики появилась даже мода на расизм. Эта публика, считающая себя генетической элитой, которая живет, непрестанно отгораживаясь от «быдла» и «генетического отребья». Скажем сразу: генетика как наука не имеет никакого отношения к моде на расизм. В природе есть и гены эгоизма, и гены альтруизма.

Английский ученый Мэтт Ридли пишет: «Карл Маркс разработал социальную систему для ангелов, и она потерпела крах потому, что мы - звери» [12, с. 559]. Во-первых, нравственные чувства и социальные инстинкты укоренены в биологии животных. Еще в начале XX в. П. А. Кропоткин выдвинул концепцию взаимопомощи (альтруизма) как важнейшего фактора биологической и социальной эволюции $[4$, с. 4]. Эволюционная генетика полностью подтвердила эту концепцию П. А. Кропоткина [2, р. 230]. Во-вторых, природа человека широка и противоречива: какие человеческие качества будут востребованы, зависит от типа общества. «Люди-звери» есть продукт определенных обстоятельств и условий жизни. Капитализм поддерживает эгопсихологию и социал-дарвинизм, поощряет войну всех против всех. Как правило, при капитализме процветают люди эгоистического склада, люди с особым психотипом и генетической алчностью.

Теоретики неолиберализма рассматривают ненасытность, алчность и бесконечность потребления как стремления, присущие самой природе человека. Меж- 
В. В. Мантатов, Л. В. Мантатова. На пути к устойчивому развитию мира: коммунитаристская стратегия жизнеустройства сообществ людей

ду тем, как показывают биологические и социальные исследования, эти пороки не являются естественными человеческими состояниями.

Как известно, в 1960-х гг. в СССР был поставлен эксперимент по коммунистическому общежитию. На Шпицбергене, где в СССР была концессия на добычу угля, был построен городок для советских специалистов. В этой колонии были свои магазины. Экспериментаторы поставили советскую колонию Шпицбергена в условия, похожие на коммунизм, - объявили, что все товары можно брать бесплатно по потребности. Сначала все бросились хватать, особенно икру. Но магазины упорно заполняли товарами. И тогда люди успокоились и стали брать ровно столько, сколько им нужно. Спустя некоторое время они стали бесплатно брать меньше товаров, чем покупали раньше.

Есть достаточно много доказательств того, что существуют реальные возможности для развития альтруистических начал жизни. И мы должны понимать: пока люди будут продолжать руководствоваться частными интересами в ущерб Общему Благу, пока они не пересмотрят неолиберальную идеологию эгоцентризма и потребительства, человечеству не избежать экологической и антропологической катастрофы.

Сегодня на Западе тотальному господству неолиберализма в информационно-идеологическом пространстве пытаются противостоять коммунитаристские концепции социальной жизни. Как известно, дискуссия «коммунитаризм versus неолиберализм» имеет широкий общественный резонанс в современном мире. По мнению теоретиков коммунитаризма, господство неолиберальной идеологии привело к восстанию и диктатуре элит, к апатии и дегуманизации масс, разложению общественных институтов и деградации окружающей среды $[15$, с. $9 ; 6$, c. $24-25 ; 7$, c. 375$]$.

В отличие от неолибералов теоретики коммунитаризма доказывают, что сообщества являются естественной средой, лежащей в основе человеческого бытия. Значит, реализация прав и свобод индивида невозможна вне сообществ. Чувство принадлежности к сообществу противопоставляется буржуазному индивидуализму. Основной задачей коммунитаризма является поиск гибких форм баланса между правами личности и правами сообществ, индивидуальной свободой и социальными обязательствами. При этом общество рассматривается не как совокупность индивидов, а как «сообщество сообществ» [15].

Коммунитаризм развивает идею морального совершенствования общества на основе возрождения традиционных ценностей, идею высокой гражданственности лидеров государств и подлинной демократической подотчетности государственных служащих. Вместо буржуазного культа потребительства предлагается нравственный проект, главное для которого - не потребление материальных благ, а «воспитание благородных качеств человека» [7, с. 375]. Социалдарвинистской концепции «войны всех против всех» противопоставляется принцип «cooperative enquiry» как способа решения спорных проблем и различных противоречий внутри сообществ. 
Идею развития моральных качеств человека развивает также философия «capabilities approach» лауреата Нобелевской премии Амартия Сена [13, с. 107109] и американского философа Марты Нассбаум [22, р. 33-34]. С коммунитаристским перфекционизмом эту философию роднит ее основная идея - идея полноценного человеческого функционирования. Основными функциональными векторами, или параметрами человеческого бытия, выступают высоко ценимые людьми блага, такие как здоровье (способность вести здоровую жизнь), образование (способность получить его), материальная обеспеченность, возможность участия в общественной и политической жизни, способность к социальному выбору и реализации своей стратегии жизни, нравственный потенциал личности. Чем больше способностей представлено в конкретной человеческой жизни, тем выше оценивается ее качество.

Как известно, философия «capabilities approach» легла в основу концепции устойчивого человеческого развития, которая поддержана многими структурами ООН. Согласно данной концепции, важнейшей целью устойчивого развития общества становится непрерывное расширение человеческих возможностей, которые каждый человек использует для улучшения качества своей жизни.

К числу теоретических заслуг философии «сараbilities approach» можно отнести требование создания социальных институтов, реализующих вышеназванные возможности человеческого развития. В этом отношении А. Сена и М. Нассбаум можно назвать последовательными коммунитаристами. По мнению М. Нассбаум, правительство должно не только устранить препятствия на пути к полноценному человеческому функционированию, но и провести радикальные институциональные изменения в обществе, в частности, перераспределение богатства. Она доказывает необходимость развития у граждан коммунитаристских качеств и эмоций (как товарищество и общность, сострадание и справедливость и т. д.), стимулирующих эти изменения и перемены. М. Нассбаум демонстрирует ущербность идеологических посылов неолиберальной экономики, которая сводит все богатство человеческих устремлений к личной материальной выгоде, а широкое экзистенциональное понятие счастья ограничивает количеством денег [22, p. 18-19].

Теоретическая заслуга теории коммунитаризма состоит в том, что она опровергла неолиберальный миф об эгоцентричной сущности человека и утвердила приоритет ценностей коммуны и кооперативного сотрудничества людей.

По сообщению журнала «Тайм», в США движение по созданию коммун приобрело форму бума; в начале столетия один из восьми американцев был членом общины. Сегодня термины «коммуна», «коммунитарность» в социальном дискурсе используются достаточно часто и, можно сказать, очень «модны».

В странах Запада широкое развитие получили предприятия с собственностью работников. Создана Европейская Федерация работников-собственников, объединяющая 50 стран. Свыше 70 стран мира законодательно закрепили права работников на участие в капитале, прибыли и управлении коллективными предприятиями. 
В. В. Мантатов, Л. В. Мантатова. На пути к устойчивому развитию мира: коммунитаристская стратегия жизнеустройства сообществ людей

Сегодня кооперативная стратегия коммунитарно-институциональных преобразований имеет солидное научное обоснование. Эволюционная наука заложила биологические основы кооперативного социализма; математические науки (теория игр, теория алгоритмов и др.) доказали бесконфликтность и эффективность кооперативных форм социальной организации. Главное достижение вычислительной математики - интернет - можно рассматривать как общую собственность, как общественное предприятие, как предпосылку нового («цифрового») социализма.

Общественные науки свидетельствуют о том, что стратегия сотрудничества и солидарности является главным условием устойчивого развития человеческих сообществ и выживания человечества. Так, например, лауреат Нобелевской премии Оливер Уильямсон доказывает, что коллективные структуры, базирующиеся на отношениях сотрудничества и взаимопомощи, представляют собой естественные формы организации общественных отношений, уходящие в глубь веков [24, p. 44-52]. Американский политолог Роберт Аксельрод обосновывает положение о том, что нравственное поведение в долговременной перспективе оказывается единственной стратегией, обеспечивающей выживание сообществ. Этот его вывод подкреплен данными компьютерного моделирования и новейших достижений математических наук [16, p. 63-68]. Лауреат Нобелевской премии Элинор Остром доказала необходимость институционализации нравственных норм и правил коллективных (кооперативных) действий как важнейшего условия устойчивого развития общества [23, р. 259]. Концепция кооперативного коммунитаризма Э. Остром возрождает понятие кооперации, соединяя кооперативную стратегию жизни эволюционной биологии и коммунитаристский метод «cooperative enquiry» (кооперативного исследовательского диалога) [11, с. 182-184].

При безусловном признании практической значимости распространения коммунитаристских идей в обществе рассчитывать на то, что они смогут стать реальной альтернативой неолиберальному индивидуализму, было бы по меньшей мере утопической мечтой. Призывы к моральному совершенствованию общества (в т. ч. правящего класса) в условиях аморального капитализма - это «как мертвым припарки». Реализация проекта коммунитаристского перфекционизма требует смены политических режимов, однако на такой радикализм сторонники западного коммунитаризма не способны. Программа западного коммунитаризма представляет собой перечень рекомендаций морально-институционального характера для различных локальных сообществ, совершенно не затрагивающий финансово-экономических и социально-политических основ капиталистического строя в целом. В условиях глобализации капитализма моральноперфекционистский проект коммунитаризма в лучшем случае возможен только в маргинализованных формах как средство приобщения индивидов к той или иной этической традиции локального значения.

В начале XX в. коммунитаристские идеи развивал русский коммунист П. А. Кропоткин. Его идеи анархо-коммунизма сегодня пользуются большой популярностью в мире. «Пусть вернется мир Кропоткина», — говорят революци- 
онно настроенные сторонники коммунитаризма. В определенном смысле можно сказать, что мир Кропоткина - это мир «высокого» коммунитаризма. Это мир, высшим приоритетом которого является Общее Благо, согласованное с благом каждого человека [5, с. 278].

Как известно, принцип коммунитарности развивал также русский философ Н. А. Бердяев. Он четко выделил два противоположных принципа хозяйственной жизни. Один принцип гласит: преследуй свой личный интерес и это будет способствовать хозяйственному развитию целого, это будет выгодно для общества, нации, государства. Второй принцип - служи другим, обществу, целому и тогда получишь все, что тебе нужно для жизни. Второй принцип соответствует христианству и его утверждает коммунизм. В этом - правота коммунизма, по мнению Н. А. Бердяева [2, с. 220].

Словом, идея коммунитаризма есть не что иное, как идея русской общинности, традиционная для русской культуры и русской философии. Тем более обидно осознавать, что правящая псевдоэлита России выбрала неолиберальный курс, антигуманный и антинародный по своей сути, предав забвению свою собственную коммунитаристскую традицию.

Как ни парадоксально, наибольшее распространение антикоммунистические лозунги получили на постсоветской территории. Распад СССР воспринимается многими интеллектуалами как крах красного (коммунистического) проекта. Однако реальное коммунистическое общество существовало слишком короткое время, чтобы делать выводы о его несостоятельности. Семьдесят лет это мизерный с точки зрения истории срок, по которому нельзя оценивать такую глобальную теорию, как коммунизм. К тому же все эти годы СССР находился в состоянии то горячей, то холодной войны, навязанной капиталистическим окружением. Одной из главных причин распада СССР явился крайний этатизм («культ государства»), порожденный внешними факторами, и как следствие - недостаточное развитие коммунитаристских (в т. ч. кооперативных) начал хозяйственной и общественной жизни.

Для Российской Федерации, из которой коммунитаристские идеалы и практики, казалось, окончательно ушли вместе с крушением Советского Союза, возвращение коммунитаризма представляется судьбоносным феноменом. Для российского исследователя коммунитаризм имеет гораздо большую ценность, чем неолиберализм, поскольку он конгениален русской культурной традиции.

Наша позиция такова. Пока политические и интеллектуальные элиты Российской Федерации не пересмотрят неолиберальную политику реформ, переход российского общества к устойчивому развитию невозможен. Мы полагаем также, что переосмысление философии коммунитаристского перфекционизма будет способствовать определению социалистических перспектив устойчивого развития российского общества.

Статья подготовлена при поддержке гранта РФФИ № 18-411-030016 p_a. 
B. В. Мантатов, Л. В. Мантатова. На пути к устойчивому развитию мира: коммунитаристская стратегия жизнеустройства сообществ людей

\section{Лuтература}

1. Барлыбаев Х. А. Введение в философию солидарности. М.: Национальная библиотека, 2016. 127 с.

2. Бердяев Н. А. Истоки и смысл русского коммунизма. М.: Наука, 1990. 224 с.

3. Кант И. К вечному миру. Соч.: в 6 т. М., 1966. Т. 6. С. 257-311.

4. Кропоткин П. А. Взаимопомощь как фактор эволюции. М.: Самообразование, 2007. $65 \mathrm{c}$.

5. Кропоткин П. А. Этика. М.: Политиздат, 1991. 83 с.

6. Лэш К. Восстание элит и предательство демократии. М.: Логос, Прогресс, 2002. $224 \mathrm{c}$.

7. Макинтайр А. После добродетели. М.: Академический проект; Екатеринбург: Деловая книг, 2000. 384 с.

8. Мантатов В. В. Стратегия Разума: экологическая этика и устойчивое развитие: в 2 т. Улан-Удэ: Бурят. кн. изд-во, 2000. 219 с.

9. Мантатов В. В., Мантатова Л. В. Стратегия Жизни: философские перспективы экологической этики: в 2 т. Улан-Удэ: Изд-во ВСГУТУ, 2015. 138 с.

10. Маркс К., Энгельс Ф. Экономическо-философские рукописи 1844 года. Часть «Коммунизм» // Сочинения. Изд. 2-е. 1974. Т. 42. С. 41-174.

11. Остром Э. Управляя общим. Эволюция институтов коллективной деятельности. М.: ИРИСЭН, Мысль, 2010. 448 с.

12. Ридли М. Происхождение альтруизма и добродетели: от инстинктов к сотрудничеству. М.: Эксмо, 2012. 330 с.

13. Сен А. Развитие как свобода. М.: Новое издательство, 2004. 425 с.

14. Урри Дж. Социология за пределами обществ: виды мобильности для XXI столетия. М.: Высшая школа экономики, 2012. 336 с.

15. Этциони А. От империи к сообществу. Новый подход к международным отношениям. М.: Ладомир, 2004. 293 с.

16. Axelrod. R. The Evolution of Cooperation. New York: Basic Books, 1984. 241 p.

17. Hobson J. M. Mann, the State and War, in John A. Hall and Ralph Schroeder (eds.) An Anatomy of Power: The Social Theory of Michael Mann. Cambridge: Cambridge University Press, 2006. 409 p.

18. Mann M. The sources of social power. Cambridge: Cambridge univ. press, 1988. Vol. 1; A history of power from the beginning to A.D. 1760. P. 510.

19. Mann M. The sources of social power. Cambridge: Cambridge univ. press, 2012. Vol. III; Global Empires and Revolution, 1890-1945. P. 190.

20. Mann M. The sources of social power. Cambridge: Cambridge univ. press, 2013. Vol. IV; Globalizations, 1945-2011. P. 197.

21. Maynard Smith J. Evolutionary genetics. Oxford: Oxford university press, 1989. P. 230.

22. Nussbaum M. Creating Capabilities: The Human Development Approach. Cambridge, Massachusetts: The Belknap Press of Harvard University Press, 2011. 237 p.

23. Ostrom E., Schroeder L., Wynne S. Institutional Incentives and Sustainable Development: Infrastructure Policies in Perspective. Boulder: Westview Press, 1993. P. 259.

24. Williamson. O. E. The Economic Institutions of Capitalism: Firms, Markets, Relational Contracting. New York: Free Press, 1985. P. 44-52. 
TOWARDS SUSTAINABLE DEVELOPMENT OF THE WORLD: A COMMUNITARIAN STRATEGY OF THE LIFE ORDER OF COMMUNITIES

\section{Vyacheslav V. Mantatov}

Dr. Sci. (Philos.), Prof., Head of UNESCO Department of Environmental Ethics, East-Siberian State University of Technology and Management 40v Klyuchevskaya St., Ulan-Ude 670013, Russia

E-mail: unesco03bur@gmail.com

\section{Larisa V. Mantatova}

Dr. Sci. (Philos.), Prof., Head of Philosophy, History and Cultural Studies Department, East-Siberian State University of Technology and Management 40v Klyuchevskaya St., Ulan-Ude 670013, Russia

E-mail: mantatovalarisa@mail.ru

The article analyzes the concept of communitarianism as an alternative to neoliberalism against the background of working out a new strategy for sustainable development of the world. Communitarianism develops the idea of moral improvement of society in terms of the revival of traditional values, the idea of high civic consciousness of state leaders and genuine democratic accountability of public servants. The leading approach to the study of this problem is the method of philosophical reflection, which allows us to identify the foundations and prospects of various strategies for managing people's communities.

In our opinion, a most realistic and legitimate, strategic and algorithmic theory of world development is a concept of sustainable development promoted by the UN; at the same time there is an immaturity of social technologies for such development. The article is of considerable practical importance for developing the ways of Russian society’s transition to sustainable development.

Keywords: strategy; life order; communitarianism; neoliberalism, sustainable development. 